\title{
A propos de la toux
}

\section{Eberhard Wolff}

Prof. Dr rer. soc., rédacteur Culture, histoire, société

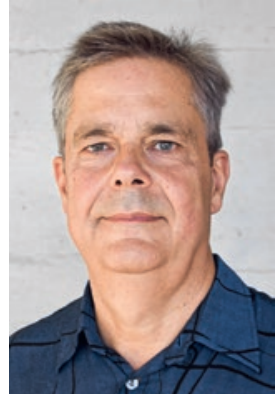

Notre matou s'appelle Herbie et je suis allergique aux chats. Si ma toux irritative ne semblait jusqu'ici déranger personne, il en est tout autre depuis ce printemps. La preuve: alors je me rendais à la boulangerie, j'ai éprouvé l'envie urgente de tousser, faisant fuir la personne arrivant en face. Un cliquet de lépreux n'aurait guère été plus efficace pour avertir de ma «dangerosité» que la petite quinte que je venais de lâcher.

Le coronavirus a changé l'image de la toux et les sentiments qui lui sont associés. Appartenant aux principaux symptômes d'une infection au nouveau virus, elle est passée de phénomène banal, révélateur d'un simple refroidissement, à déclencheur d'une peur viscérale.

Mécanisme remarquable qui permet d'expulser les corps étrangers des voies respiratoires, la toux fait partie des fonctions corporelles utilisées au quotidien. À une extrémité, elle reflète l'insignifiance médicale («Toussotez!»), à l'autre, elle est un messager de mort imminente. Un motif de narration utilisé depuis la nuit des temps, devenu aujourd'hui un cliché cinématographique: «Celui qui tousse meurt» [1].

Quand les tableaux cliniques des différentes formes de toux n'existaient pas encore, celle-ci était une notion floue et se référait souvent à un "état souffreteux". Les débuts de la médecine moderne ont vu l'apparition des différentes formes de toux, qui ont peu à peu intégré la pensée courante et façonné l'image générale de la toux. On pourrait parler de "toux de référence» ayant marqué chacune une époque.

1 Stillich S. Wer hustet,

1 Stillich S. Wer hustet,
stirbt. Der Spiegel online. 16.9.2009.

2 Cf. aussi «Raucherhusten Blues» de Insterburg \& Co, 1973.

3 Ehrensperger A. AtemWege. Erkundungen zu Luftverschmutzung, Atemnot und Achtsamkeit. Zürich: Chronos; 2020

4 Vogt W. La toux. Histoires vraisemblables et invraisemblables. Traduit de l'allemand par François Conod. Orbe: Bernard Campiche, 2010 (paru en allemand en 1965).
Prenons la coqueluche. Les pauvres enfants qui l'attrapaient étaient quasi asphyxiés par leur incessante toux sifflante, suscitant la compassion, la peur et le désespoir. Comme aujourd'hui la fibrose cystique.

Dans les régions minières, la toux caractéristique était celle, virile, des mineurs avec leurs poumons chargés de suie ou de silice. La pitié s'accompagnait du respect et de l'admiration pour ces hommes passant leur vie sous terre et accomplissant un travail éreintant.

Parmi les nombreuses images liées à la toux phtisique de l'époque des fondateurs, mieux connue sous le terme de tuberculose, on peut évoquer le roman de Thomas Mann, La Montagne magique (1924), qui s'ouvre sur une scène dans un sanatorium et brosse le portrait de la bavarde Madame Stöhr avec sa toux «joyeuse» et de la pauvre Leila Gerngross, que ses violentes attaques de toux finissent par terrasser.
La tuberculose a été décisive dans l'avènement de notre époque bactériologique, attachant à la toux l'idée indissociable des risques que le malade fait courir à son entourage. A la peur suscitée par la maladie s'ajoutait désormais la peur de la contagion. Des affiches de prévention dépeignaient la toux comme vecteur de propagation et en appelaient à la responsabilité individuelle - et au sentiment de culpabilité - de tous les citoyens, notamment durant le terrible épisode de la grippe espagnole.

Une fois les maladies infectieuses sous contrôle - du moins en Occident - dans les années 1970, l'attention s'est portée sur la toux du fumeur [2]. Une toux suscitant la réprobation et le dégoût. Lorsque la guerre contre le tabac a été déclarée, la toux du fumeur est devenue un critère d'addiction, de morale sanitaire et de self control.

A la fin du siècle dernier, la médecine a regroupé une série de manifestations cliniques sous la bannière généraliste de la BPCO (bronchopneumopathie chronique obstructive). La pollution atmosphérique comptant parmi les facteurs déclencheurs de ce type d'affections [3], la "faute» a alors quitté la sphère individuelle pour se centrer sur notre société industrielle moderne. La toux a continué à faire partie de l'imaginaire collectif. En témoigne La Toux du psychiatre et romancier bernois Walter Vogt, écrite en 1965. Elle décrit le cas du haut fonctionnaire Felix Wieder, de plus en plus empêtré dans les rouages du système médical kafkaïen et qui finit par en mourir. Ce n'est pas un hasard si Vogt a choisi ce symptôme bénin comme point de départ de son récit [4].

Aujourd'hui, difficile de parler de symptômes bénins. $\mathrm{Au}$ temps du corona, la toux nourrit à nouveau une peur viscérale. Peur d'attraper le virus, mais plus encore de susciter l'opprobre généralisé en devenant un superpropagateur. «Maman, j'ai plus le droit de tousser?» entendais-je récemment un enfant dans la rue. La toux disparaît ainsi quasiment de l'espace public.

Quand je fais mes longueurs à la piscine, je me débrouille désormais pour tousser la tête sous l'eau. Et un collègue m'a dernièrement avoué recourir au même stratagème. Après tout, les coquilles Saint-Jacques ont toujours fait comme ça. Tant que le coronavirus continuera de sévir, je tousserai sous l'eau. Et Felix Wieder aurait été bien inspiré d'en faire de même. 